\title{
Global Perspectives on Regulatory Measures and Collection Procedures for Electronic Waste: A Critical Assessment
}

\author{
Khanna ${ }^{1 *}$, Park M², Cayumil R ${ }^{3}$, Mishra SK ${ }^{4}$ and Mukherjee PS 4 \\ ${ }^{1}$ School of Materials Science and Engineering, University of New South Wales, Australia \\ ${ }^{2}$ Australian School of Architecture and Design, University of New South Wales, Australia \\ ${ }^{3}$ Facultad de Ingenieria, Universidad Andres Bello, Chile \\ ${ }^{4}$ Institute of Minerals and Materials Technology, Advanced Materials Technology \\ Department, India
}

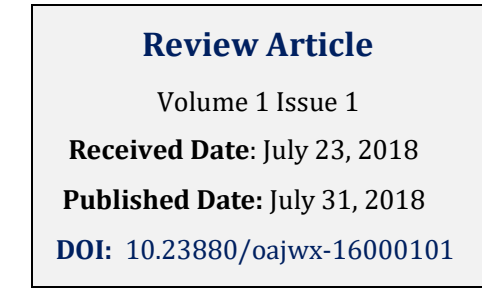

*Corresponding author: Rita Khanna, School of Materials Science and Engineering, The University of New South Wales, Sydney, Australia, Tel No: 61-2-93855589; Email: rita.khanna66@gmail.com

\begin{abstract}
Extensive usage, new designs, rapid upgrades and short life-spans of electronic devices has resulted in ever growing generation of electronic waste (e-waste) worldwide. Burgeoning volumes of e-waste are becoming a global issue of great concern with developing and poor economies rapidly catching up with developed nations. This article presents an overview of regulatory measures being developed and operated across Europe, Asia, Oceania, Americas and Africa. Developed economies are more likely to have e-waste regulations and enforceable management systems in place but are relatively inefficient in e-waste collection as compared to poor and developing nations. E-waste collection occurs through channels broadly described as formal and informal sectors. The formal collection occurs largely in developed economies often managed by waste management services operating within national or local e-waste regulations. Informal collection in Africa, China, India and other Asian countries encompasses a range of unregulated and unreported collection arrangements including door to door brokers between households and mid-level scrap dealers, dismantlers and repairers. The opportunities and challenges for the management of e-waste remain complex and vary depending on the local political, cultural and socio-economic waste management issues. With recycling rates still below $20 \%$, these need to evolve further for environmentally and economically sustainable management of e-waste.
\end{abstract}

Keywords: E-Waste; Recycling; Regulations; Formal Sector; Informal; Waste Collection; Global Trends

\section{Introduction}

Escalating consumption, dependence on electronic gadgets and products in everyday life, rapid upgrades and product obsolescence has led to electronic waste (e- waste) becoming one of the fastest growing solid waste streams in the world. Approximately 45 million tonnes of e-waste were generated globally in 2016 and are estimated to grow at $\sim 3-5 \%$ per annum $[1,2]$. More than $70 \%$ of the world population presently owns a mobile 


\section{Open Access Journal of Waste Management \& Xenobiotics}

phone; the total number of mobile phones is expected to exceed 5 billion by 2019 [3]. Due to a downward trend in costs and increasing affordability, users from the third world and developing nations are quickly catching up with developed nations in the use of electronic gadgets like TVs, tablets, smart phones, laptops, portable/wearable electronics, networked devices, computers etc. A tendency towards disposal at the slightest inconvenience, expensive repairs, new product designs and aggressive marketing etc. is resulting in large volumes of end-of-life electronic products being generated across the globe.

Although e-waste has been piling up over several decades, its environmental impact and management has become an issue of concern in recent years. The central processing unit of electronic devices, waste printed circuit boards (PCBs), are a highly complex mixture of ceramics, metals and polymers; up to 1000 different compounds could be present in some obsolete equipment [4]. PCBs typically contain $40 \%$ of metals, $30 \%$ of organics and $30 \%$ ceramics. However, there is a great variance in composition of PCB wastes coming from different appliances, from different manufacturers and of different age. After removing batteries and capacitors, PCBs from computers/TVs may contain up to $70 \%$ organics whereas PCBs from mobile phones contain $\sim 20 \%$ organics [5]. These heterogeneous compositions can include valuable constituents as well as hazardous and toxic elements or compounds [6]. Poor product design and overly complex construction makes the recovery and separation of materials quite difficult; toxic and valuable materials are often bonded to non-toxic valuable materials making recycling labour intensive and quite expensive [7].

Due to inherent complexity of these devices, there is presently no standard, well-established process to treat a wide variety of e-waste. Hazardous compounds present in waste electronics can get released when end-of-life equipment are dumped, disposed of or processed inappropriately. Current processing approaches are focused predominantly on the recovery of copper and precious metals as their recovery is economically attractive due to significant quantities present in e-waste $[8,9]$. A standard sized cathode ray tube (CRT) monitor can contain up to two kilos of lead; a tonne of discarded mobile phones (without batteries) can yield up to 300 grams of Gold - a far greater yield than the most efficient gold mine [10]. Some of the methods used to achieve these goals include open burning, manual dismantling/disassembly, mechanical processing, pyrometallurgy, hydrometallurgy etc $[11,12]$. Wherever the operation of these processes is inadequate or unsafe, it can lead to the generation of additional hazardous compounds and may also release highly toxic emissions [13]. When discarded these products present considerable environmental and health challenges-far greater than for many other categories of consumer waste. Approximately 40 per cent of the heavy metal contamination in landfills comes from electronic waste [14].

Inadequate as well as unsafe processing of e-waste can have a detrimental impact in regions surrounding the recycling areas in the form of soil contamination, vegetation, water and air quality, flora and fauna as well as health of human population [15]. Hazardous e-waste contaminants can be divided in three categories: primary, secondary and tertiary contaminants. Primary contaminants include among others lead, mercury, lead, nickel, cadmium, flame retardants that are present initially in the e-waste; secondary contaminants include by-products and/or residues after waste processing such as spent acids, toxic compounds, poly aromatic hydrocarbons (PAHs), and the tertiary contaminants include leftover reagents or compounds after processing [16-20]. In an e-waste processing facility in Ghana, high levels of $\mathrm{Fe}, \mathrm{Sb}, \mathrm{Pb}$ and $\mathrm{As}$ were detected in site workers [21]. People living near a recycling site in China showed much higher levels of trace and heavy metals lead and copper as compared to typical concentrations in general population [22]. Higher presence of lead can affect growth, increase bone re sorption and osteoporosis [23]. Workers in an informal e-waste recycling site were found to suffer from back and other pains and showed a higher incidence of respiratory diseases [24]. Similar trends have been reported from e-waste processing facilities in India.

In the developed nations, the problem of how to manage e-waste is typically regulated through 'Extended Producer Responsibility' (EPR) based schemes that often involve a combination of roles undertaken by government, industry and local authorities. Meanwhile, in many developing regions of the world, where regulations do exist, management of collection and recycling of ewaste is poorly enforced. This is partly due to the way ewaste is collected and processed. In emerging economies e-waste is collected and recycled by the many (informal) individual or small independent collectors and traders. The recycling rates of e-waste continue to remain quite low (only up to $20 \%$ ) in the formal as well as the informal sectors [25]. Regulations and collection of e-waste are of crucial importance in managing highly complex, ubiquitous, and hazardous electronic waste. In this article, we present an in-depth review and assessment on regulations on managing e-waste in different regions of the world, collection procedures and trans-boundary movements between developed and developing nations. 


\section{Open Access Journal of Waste Management \& Xenobiotics}

\section{Management and Regulation of E-waste}

Many nations now recognise the importance of managing e-waste, whether generated domestically or imported, and have introduced regulations for the recovery, treatment and recycling of e-waste. The European Union (EU) has been a leader in the field with many nations basing their regulations on the EU e-waste regulation model [2]. The EU Waste Electrical and Electronic Equipment Directive (WEEE Directive) relies upon the principle of EPR, a take-back system environment policy approach that attributes responsibility to manufacturers, distributors and retailers to taking back products after use, and is based on polluter-pays principles [26]. First implemented in the developed world, EPR is regarded as an efficient waste management policy to improve e-waste recycling and is the starting point for most e-waste regulations worldwide. EPR approaches to managing e-waste are increasingly being adopted around the world [27]. An OECD survey of 384 EPR programs found that $70 \%$ had been adopted between 2001 and 2013, with Chile, Mexico, Brazil, Argentina and Colombia adopting EPR programs within the past four years. Other countries like China, India and Indonesia have either started or recently commenced EPR programs [28].

Key issues for e-waste management can be complex, challenging and different for each geographical region. Primary differences in e-waste management and recycling practices are the starkest between the emerging and developed economies. These differences are further complicated by local practices and arrangements within each sub-region, nation and municipal locations. Moreover, these different approaches to e-waste management, collection and recycling practices, and increasing globalisation have given rise to a bourgeoning trade in e-waste invariably from developed nations to developing regions of the world. To manage this international trade, multi-lateral agreements have been put in place to regulate transboundary movements of ewaste and hazardous substances. The 'Basel Convention' on the 'Control of Transboundary Movements of Hazardous Wastes and their Disposal' is one of the most prominent agreements. It aims to minimise waste generation at source, to promote environmentally sound management practices, advocate for disposal close to source (proximity principle), and most significantly, monitor and regulate the transboundary movements of hazardous waste [7]. Despite 178 nations being signatories to the agreement, a significant proportion of the international trade remains undisclosed and unregulated [3].

\section{Regional Review of E-waste Regulations}

To reduce the increasing volumes of e-waste going to landfill or recycled by unsafe and environmentally damaging processes many regions and nations have introduced regulations for managing e-waste. There are significant overlaps as well as differences in regulations around the globe. Regions selected include developed nations (Europe, Oceania, North America, Japan, Korea etc.), transient and emerging economies (Asia, South America) and poor nations (Africa). These are detailed below.

\section{Europe}

The European Union is often regarded as having the most comprehensive and uniform e-waste collection legislation. It takes a directive framework approach, where the European Commission (EC) establishes Directives that the Member States transpose into their own laws. The Waste electric and electronic equipment (WEEE) directive is a uniform regulation for the collection and processing of e-waste first introduced in 2002 $[26,29]$. This legislation is linked with the 'Restriction of Hazardous Substances Directive' (RoHS) that limits the use of certain hazardous materials in the manufacture of electronic and electrical equipment and the regulation on 'Registration, Evaluation, Authorisation and Restriction of Chemicals' REACH. During the first few years implementation the WEEE directive, it was found that majority of e-waste remained completely unaccounted for due to loopholes and difficulties in enforcement [7]. It was revised in 2012 and an enhanced directive is proposed for 2019. This will set higher recycling targets and broaden the scope for generated e-waste [30]. Of the various European member states, Germany has adopted a comprehensive and forward-thinking e-waste management system [31]. The Netherlands is another EU nation leading in the collection and management of ewaste. While more than $75 \%$ of large household appliances were collected, less than $45 \%$ of available small household appliances were collected [32]. In other parts of Europe, especially non-EU member states, the legislation in Balkans and Russia remains patchy or nonexistent along with poor infrastructure and recycling schemes [30].

\section{Asia}

The Asian region is a global hotspot for the growth in e-waste generation and a major destination for the world's e-waste. China (6.0 Mt), Japan (2.2 Mt) and India (1.7 Mt) generate the most e-waste by weight in the region [30]. Furthermore, domestic generation of e-waste 
in the region is also escalating. India has one of the fastest-growing electronics industries in the world; while an estimated that 3.62 million tonnes of televisions, computers, refrigerators, washing machines and air conditioners were discarded by Chinese consumers in 2011 alone [2,22]. This is driven by the fastest growing consumption rates in the world of EEE devices and China being a major destination global destination for e-waste. Regulation and management of e-waste in the region remains inconsistent and varies enormously throughout the region. Japan, one of the first countries in the world to adopt the Product stewardship scheme for e-waste, is the most developed and advanced nation in e-waste collection in South East Asia. Japan along with Taiwan was one of the first nations in the region to legislate and implement an EPR scheme for e-waste management $[3,30]$. It has developed a framework of regulations setting recycling targets to certain product categories. Regarded as a strong legal framework with a capacity to recover even the smallest electronic gadgets, it has helped advance e-waste collection, urban mining as well as recycling infrastructure [30].

China is the global manufacturing base for many categories of EEE. It is estimated that China treats about $70 \%$ of the world's e-waste; this volume includes a substantial domestic contribution from China itself, which is now the second largest generator of e-waste after the United States [30]. In 2006 China introduced the Measures for Administration of the Pollution Control of Electronic Information Products ("China RoHS") and in 2009 the Ordinance on the Administration of the Recovery and Treatment of Waste Electrical and Electronic Products ("China WEEE"). This requires manufacturers and importers to pay a fee to a government fund to subsidise the waste recovery and recycling [26]. The Chinese Government has also started to regulate the e-waste recycling industry in Guiyu and other designated e-waste processing hotspots. In other nations, even where legislation does exist, formal collection rates are poor and improper handling and the illegal trade in e-waste remain prevalent [33]. China, Taiwan, India, Japan, Hong Kong, South Korea, Vietnam all have national e-waste related regulations, but management and compliance vary and often only applied to isolated formal (regulated) recycling operations [30]. These sectors have to compete with dominant and widespread informal collection methods.

India along with China is a major regional destination for the global trade in e-waste, in addition to their rapidly growing domestic generation of e-waste. Compared to China, India's e-waste legislation has been somewhat limited [34]. The Indian Government is attempting to formalise and control the informal recycling sector through recently introduced regulations. Their e-waste management rules (2016) are based upon the EPR scheme, setting collecting and recycling targets. The Indian scheme assigns management and reporting responsibilities to manufacturers to recycle e-waste and minimise environmental damage. It is uncertain how this will operate with the dominance of informal e-waste recycling in India. In general, extended producer responsibility-based schemes in most Asian countries are difficult to implement as it is hard to determine who is the real producer or importer of EEE [34].

\section{Oceania}

While the total amount of e-waste in the region is relatively small comparted to other parts of the world, Australia and New Zealand generate amongst highest amount of e-waste per person in the world [35]. Australia introduced the 'Product Stewardship Act (2011)'to provide a legislative framework for national e-waste stewardship scheme [30]. E-waste regulation was created only for certain categories of EEE, notably televisions and computers. The 'National Television and Computer Recycling Scheme (NTCRS)'requires companies that manufacture or import TVs or computers to take responsibility for recycling products at end of life by joining and supporting a government-approved service [26]. A review of national legislation is proposed for 2017 to consider expanding the scheme to include the other categories of EEE, to better represent a large majority of e-waste and increase recycling targets [36]. Meanwhile independent initiatives and state government base schemes attempts are being carried out to complement ewaste collection by broadening EEE categories. Mobiles muster is a government accredited not-for-profit mobile phone and phone battery recycling programme, while the South Australian state government has a Zero Waste act attempting to ban e-waste from landfills [26,37].

\section{Americas}

By any measure the United States generates the most e-waste in this region. In 2014, the United States generated 7.1 metric tons of e-waste, compared to 1.4 metric tons in Brazil and 1 metric ton on Mexico [30]. In Central and South America Costa Rica, Peru, Bolivia and Ecuador have implemented e-waste collection and recycling legislation, while Brazil and Chile have laws pending approval. Both United States and Canada have no national legislation and the United States is not a signatory to the Basel convention [7]. In the United States officially reported collected e-waste (often restricted to IT devices) only represents $15 \%$ of the total e-waste generated in 2012. A contributing reason for low 
recycling rates is the lack of any federal legislation to manage the collection and recycling of e-waste. Despite this, twenty-five individual states have some form of ewaste recycling legislation that covers 65 per cent of the U.S. population. Generally, many state schemes are based upon a product stewardship model for computer equipment, monitors and televisions requiring produces the manufacturers to pay an annual registration fee. In California consumers pay a recycling fee when purchasing of specific types EEE [38].

\section{Africa}

Despite Africa's comparatively modest, but growing domestic generation of e-waste, it is a destination for the global trade in e-waste. Regions, particularly Western Africa, have become a dumping ground for e-waste, often illegally exported from many regions of the world. Dramatic and alarming reports emanating from Ghana and Nigeria highlight the appalling environmental and working conditions in which e- waste is processed. This work is undertaken on an informal basis and in the absence of any enforceable regulation or e-waste management infrastructure. Imported e-waste is first sorted into what can be repaired, sold or scavenged for parts. Toxic material recovery recycling is dangerous and often undertaken by the poorest in those communities, including children. Open burning for the recovery of various metals from e-waste takes place in makeshift dumpsites. Cameroon and Nigeria have national e-waste related legislation, while others have draft legislations pending approval. Nigeria introduced regulations in 2011 requiring manufacturer's importers, distributors and all retailers to take back end of life EEE for collection by accredited recycles [38]. African national e-waste regulations remain poorly implemented. Additionally, International treaties such as the Basel Convention, which aims to protect nations such as Ghana from the illegal trade of hazardous waste and the Bamako Convention, banning of hazardous e-waste trade within Africa, often appear ineffectual.

\section{E-waste Collection}

Of the total amount of e-waste generated globally in 2014 , only $15.5 \%$ or 6.5 million tonnes was formally collected and treated. Around $75 \%$ of global e-waste is either dumped in landfills or remains unaccounted for. Ewaste collection occurs through various channels broadly described as formal and informal sectors. Formal collection largely occurs in developed economies. It is often managed by waste management services that operate within national or local e-waste regulations and report collected and treated waste to government.
Informal collection encompasses a range of unregulated and unreported collection arrangements. In developed economies e-waste collection is often mixed in other scrap materials or ends up in non-separate collected waste that is incinerated or land filled. The remainder is exported to developing regions of the world where the most significant proportion of e-waste processing is undertaken by a burgeoning informal recycling sector. In India and China 95\% of e-waste is collected and processed by informal sector recyclers [34]. In Ghana $85 \%$ of e-waste is collected in informal sector that employs more than 30,000 people. These informal sector workers lack labour standards and rights, and often experience poor health and environmental problems [7]. But these operations also play a vital role supporting the global trade and recycling of e-waste and providing income to people who would otherwise face even greater poverty [39]. The following section presents a comparison of both formal and informal collection methods in a selection of nations.

\section{Japan}

Japan is one of the most advanced nations in e-waste collection and processing. E-waste collection is a highly regulated and established scheme. Japanese e-waste management is based upon a user pay scheme -pay to throw. Consumers pay a fee to support recycling either in the purchase price of new products or at disposal of EEE. E-waste collection rules oblige consumers to return their e-waste to designated collection stations, retailers or post offices for a fee [3]. At each stage of the process, the government ministry in charge of the waste management monitors the fee collection process [40].

\section{China}

In contrast to Japan, most e-waste recycling in China is undertaken by an extensive and well established multitiered informal recycling sector [34]. The e-waste recycling chain starts with collection by informal collectors purchasing e-waste directly from households and businesses or through opaque means of illegal imports. China is presently a major destination for illegally imported e-waste [33]. Domestic e-waste collection is focused mainly on urban and coastal regions with larger populations. Collectors, often migrant workers from rural areas, operate as door to door brokers between households and mid-level scrap dealers, dismantlers and repairers. They negotiate a price to buy and collect household items ranging from plastic, paper and metal scraps to household appliances and other EEE [41]. This collected waste is then sold to other informal recyclers for repair, refurbishment and dismantling. Despite significant development of formal recycling pilot 
projects, these often struggle to complete and cannot match the price or service informal waste peddlers offer households and businesses. Domestic e-waste collection is mostly processed in the informal sector across China.

\section{India}

India, along with China, is another major destination for the global trade in e-waste in addition to a rapidly growing domestic e-waste. A vast majority of this waste is recycled and processed by a distributed network of informal sector that collects, dismantles and recycles ewaste, while mostly operating outside of any regulation or formal organisational system. Informal sector collectors that operate door-to-door can offer higher prices than the few formal regulated recyclers that are starting to enter the market. Informal recyclers can extract valuable metals using crude processes that are often unsafe and environmentally damaging. However, the efficiency of collection services provided by this sector is remarkably successful, especially in contrast to e-waste collection rates in most developed economies. Approximately 95\% of total e-waste is collected and dismantled by individual or family groups crap collectors or rag pickers. Generally, they sell dismantled products and parts to other informal downstream recyclers for further refurbishment, material extraction and eventually to businesses as feedstock for new manufacturing. For larger e-waste items such as refrigerators and air-conditioners, these are usually collected from households by small entrepreneurial business operators who can provide transport. At each stage of recycling chain, from collection of WEEE to elemental material extraction, value is added enabling employment and sustaining the system.

Formalised e-waste collection and drop-off services have started to appear in India but struggle to complete with scrap collectors who are widely distributed and pay households for their waste. In Bangalore, nicknamed the Silicon Valley of India, various initiatives have been piloted for the collection of e-waste by providing drop-off locations for e-waste as well as providing commercial services for waste collection from businesses and institutions. Some more novel methods include a mobile e-waste pick-up vehicle (auto rickshaw) and collection units placed at various post offices.

\section{Australia}

Australia's approach to collecting e-waste is formalised through the National TV and Computer Recycling Scheme (NTCRS) as a result its 2011 Extended Producer Responsibility (EPR) legislation [36]. The scheme is co-regulated between government and industry and establishes recycling targets (collection targets) for
TVs and computers but excludes many other types of WEEE. This means that overall recycling of e-waste in Australia amounts to only $8.7 \%$ of the total domestic generated e-waste. The strength of the scheme has been upstream with the collection and storage of TVs and computer e-waste. Some limited disassembly takes place locally, but a significant remainder is exported for further downstream processing. Complimentary industry and voluntary collection schemes also exist in Australia. Mobile Musters provide drop-off at various retail locations, post offices and institutions throughout Australia in addition to pre-paid satchel post service.

\section{Africa}

Dramatic and alarming reports emanating from Ghana and Nigeria highlight the appalling environmental and working conditions in which e-waste is being recycled. In Ghana, where no enforceable legalisation exists, it is estimated that over $95 \%$ of end of life EEE is collected with almost no e-waste ending up mixed with other domestic waste [40]. This remarkable collection rate stands in stark contrast with other nations. For example, $\mathrm{EU}$, the region with the most established e-waste regulations, struggles to collect more than $30 \%$ end of life EEE. Meanwhile, in Ghana, this work is mostly undertaken on an informal basis. Imported e-waste is first sorted into what can be repaired, sold or scavenged for parts. What cannot be used is dumped for recycling. This recycling is dangerous and often undertaken by the poorest in those communities, including children. Open burning in makeshift dumpsites is favoured for the recovery of various metals. In the absence of national legislation and management, the Basel Convention on the control of transboundary movements of hazardous wastes and their disposal has been equally ineffectual in slowing this trade.

\section{Impact of Informal Collection and Recycling}

Informal e-waste recycling in many regions exists as an opaque and loosely structured economy from collecting, sorting and on selling to sold to downstream dismantlers, repair shops and recyclers. Each entity at each stage extracts value out of the waste. Collected ewaste can be sorted into products that can be refurbished or repaired for resale. Adam Minter has written extensively about the benefits of this green economy in China pointing out the impact of unregulated market economy, small business enterprises and structures driving e-waste repair and reuse of electronic components [42]. Unrepairable electronics can be used for parts for resale with the remainder sold on for materials recovery. A dominant feature of the e-waste 
recycling in emerging economies is the role of collecting, dismantling and recycling by a vast, widely distributed and unregulated informal sector. Despite the serious negative health and environmental impacts, a much more nuanced view is required to understand not just these disadvantages, but also the advantages and services offered by this sector. An early study comparing e-waste recycling in Switzerland and in India found that e-waste collection has positive impacts for employment in India while negative impacts for downstream recycling [43]. Informal collection and recycling plays a vital role supporting the global trade and recycling of e-waste. Of the various recycling activities associated with the collection, sorting, dismantling, and materials recovery by the informal sector, it is the end of recycling line where the most environmental and health impacts occur [2].

At the macro level, the differences in e-waste collection and recycling practices around the world are most significant between developed and emerging economies. Developed economies, are more likely to have e-waste regulations and emerging economies often offer little regarding regulation or enforceable management systems. This work is primarily undertaken by informal and unregulated recyclers. This vast and widely distributed informal e-waste recycling sector is vastly more efficient and effective at collecting and recycling ewaste than developed economies. They often operate door-to-door and are distributed throughout towns, cities and regions. They offer better prices and service compared to many Government and industry regulated schemes. A comparison of the positive and negative attributers between formal and informal e-waste recycling activities at various stages is presented in the table below

\begin{tabular}{|c|c|c|}
\hline $\begin{array}{c}\text { E-waste } \\
\text { Management }\end{array}$ & Formal sector & Informal sector \\
\hline Collection & poor & good \\
\hline Data collection & poor & poor \\
\hline Product reuse & poor & good \\
\hline $\begin{array}{c}\text { Materials recovery } \\
\text { safety }\end{array}$ & good & poor \\
\hline Materials purity & good & poor \\
\hline
\end{tabular}

Table 1: Recycling of e-waste in the formal and informal sectors.

\section{Concluding Remarks}

There are many contributing factors to the growth in e-waste. Technological change, the proliferation of electronic devices into new product sectors, expanding communications networks and increased affordability, all contribute to the massive escalation in the consumption of electronic devices. Associated to these circumstances are diminishing life spans and subsequent disposal as ewaste [44]. The opportunities and challenges for the management of e-waste are complex and vary for each geographical region. The most dramatic differences exist between the emerging and developed economies. These differences are further enhanced by local practices and arrangements within each sub-region. In general, developed economies are more likely to have e-waste regulations and enforceable management systems in place, but paradoxically fail to match in volume and efficiency the amount of collected e-waste. It is hard to accurately measure this disparity due to insufficient reporting of opaque international trade in e-waste [45]. But it is claimed that only $15.5 \%$ of global e-waste generated in 2014 was reported as formally treated by national take-back programs and schemes.

Caution has been expressed on the reliance of adopting e-waste regulations, modelled upon developing nation's regulations without taking into context the local political, cultural and socio-economic waste management issues [3]. A distinction between the benefits of collection and the dangers of downstream processing need to be more clearly defined. There are clear environmental and social advantages for the informal sector to focus upon the collection of e-waste. A StEP white paper (2016) declares, "If an informal collection system exists, use it to collect all e-waste, and ensure e-waste is sent to licensed recyclers through incentives" [36]. Any downstream ewaste recycling needs to adhere to higher environmental standards and accountability.

\section{Acknowledgement}

Authors gratefully acknowledge Department of Industry, Innovation, Science, Research and Tertiary Education, Australia, and Department of Science and Technology (DST) India for providing financial support for this project under the Australia-India Strategic Research Fund Round 6.

\section{References}

1. Baldé CP, Forti V, Gray V, Kuehr R, Stegmann P (2017) The Global E-waste Monitor, United Nations University (UNU), International Telecommunication Union (ITU) \& International Solid Waste Association (ISWA), Bonn/Geneva/Vienna pp: 1-116.

2. Pariatamby A, Victor D (2013) Policy trends of ewaste management in Asia. Journal of Material Cycles and Waste Management 15(4): 411-419. 
3. Honda S, Khetriwal DS, Kuehr R (2016) Regional Ewaste Monitor: East and Southeast Asia, United Nations University VIE-SCYCLE, Bonn, Germany.

4. Cayumil R, Khanna R, Ikram-Ul-Haq M, Rajarao R, Hill A, et al. (2014) Generation of copper rich metallic phases from waste printed circuit boards. Waste Management 34(10): 1783-1792.

5. Saini R, Khanna R, Dutta RK, Cayumil R, Ikram-Ul-Haq $\mathrm{M}$, et al. (2017) A Novel Approach for Reducing Toxic Emissions during High Temperature Processing of Electronic Waste. Waste Management 64: 182-189.

6. Grossman E (2006) High Tech trash: Digital devices, hidden toxics, and human health. US: Island press 114(8): A500.

7. Lundgren K (2012) The global impact of e-waste: Addressing the challenge. International Labour Organization, Switzerland.

8. Cayumil R, Khanna R, Rajarao R, Mukherjee PS, Sahajwalla V (2016) Concentration of precious metals during their recovery from electronic waste. Waste Management 57: 121-130.

9. Veit H, Bernardes A (2015) Electronic wasteRecycling techniques. Topics in mining, metallurgy and materials engineering, Springer, Switzerland.

10. Hagelüken C (2010) Sustainable metals recycling from waste electronics-opportunities \& challenges in a global environment. South Pacific Regional E-waste Workshop Brisbane, Australia.

11. Cui J, Zhang L (2008) Metallurgical recovery of metals from electronic waste: a review. J Hazard Mater 158(2-3): 228-256.

12. Robinson BH (2009) E-waste: An assessment of global production and environmental impacts. Sci Total Environ 408(2): 183-191.

13. Musson SE, Vann KN, Jang YC, Mutha S, Jordan A, et al. (2006) RCRA toxicity characterization of discarded electronic devices. Environ Sci Technol 40(8): 27212726.

14. Rajarao R, Sahajwalla V, Cayumil R, Park M, Khanna R (2014) Novel Approach for Processing Hazardous Electronic Waste. Procedia Environmental Sciences 21: 33-41.
15. Cayumil R, Khanna R, Rajarao R, Ikram-Ul-Haq M, Mukherjee PS, et al. (2016) Environmental impact of processing electronic waste: Key issues and challenges in "E-Waste in Transition-From Pollution to Resource", edited by Florin-Constantin Mihai. Intech, Croatia pp: 9-35.

16. Song Q, Li J (2014) A systematic review of the human body burden of e-waste exposure in China. Environment International 68: 82-93.

17. Tue NM, Sudaryanto A, Minh TB, Isobe T, Takahashi S, et al. (2010) Accumulation of polychlorinated biphenyls and brominated flame retardants in breast milk from women living in Vietnamese e-waste recycling sites. Sci total environ 408(9): 2155-2162.

18. Mc Culloch A, Midgley PM, Ashford P (2003) Releases of refrigerant gases (CFC-12, HCFC-22 and HFC-134a) to the atmosphere. Atmospheric Environment 37(7): 889-902.

19. Zheng X, Xu F, Chen K, Zeng Y, Luo X, et al. (2015) Flame retardants and organochlorines in indoor dust from several e-waste recycling sites in South China: composition variations and implications for human exposure. Environment international 78: 1-7.

20. Li Y, Jiang G, Wang Y, Wang P, Zhang Q (2008) Concentrations, profiles and gas-particle partitioning of PCDD/Fs, PCBs and PBDEs in the ambient air of an E-waste dismantling area, southeast China. Chinese Science Bulletin 53(4): 521-528.

21. Asante KA, Agusa T, Biney CA, Agyekum WA, Bello M, et al. (2012) Multi-trace element levels and arsenic speciation in urine of e-waste recycling workers from Agbogbloshie, Accra in Ghana. Science of the Total Environment 424: 63-73.

22. Wang T, Fu J, Wang Y, Liao C, Tao Y, et al. (2009) Use of scalp hair as indicator of human exposure to heavy metals in an electronic waste recycling area. Environ Pollut 157(8-9): 2445-2451.

23. Yang H, Huo X, Yekeen TA, Zheng Q, Zheng $M$, et al. (2013) Effects of lead and cadmium exposure from electronic waste on child physical growth. Environ Sci Pollut Res Int 20(7): 4441-4447.

24. Gutberlet J, Baeder AM (2008) Informal recycling and occupational health in Santo André, Brazil. Int J Environ Health Res 18(1): 1-15. 


\section{Open Access Journal of Waste Management \& Xenobiotics}

25. Wang J, Xu Z (2015) Disposing and Recycling Waste Printed Circuit Boards: Disconnecting, Resource Recovery, and Pollution Control, Environ Sci Technol 49(2): 721-733.

26. Lewis H (2016) Product stewardship in action: the business case for lifecycle thinking, Greenleaf Publishing, UK.

27. Kiddee P, Naidu R, Wong M (2013) Electronic waste management approaches: An overview. Waste Management 33(5): 1237-1250.

28. OECD (2014) Issues Paper-The State of Play on Extended Producer Responsibility (EPR): Opportunities and Challenges. Global Forum on Environment: Promoting Sustainable Materials Management through Extended Producer Responsibility (EPR) 17-19 June 2014, Tokyo, Japan.

29. European Parliament (2002) Directive 2002/96/EC of the European Parliament and of the Council of 27 January 2003 on waste electrical and electronic equipment (WEEE).

30. Baldé CP, Wang F, Kuehr R, Huisman J (2015) The global e-waste monitor-2014. United Nations University, IAS - SCYCLE, Bonn, Germany.

31. Lawhon M, Salehabadi D (2013) Fixing the e-waste problem: An exploration of the socio materiality of ewaste. In Solving the e-waste problem: An interdisciplinary compilation of international e-waste research. (Ed by Sinha Khetriwal, Luepschen and Kuehr).United Nations University Press, Tokyo.

32. Huisman J, van der Maesen M, Eijsbouts RJJ, Wang F, Baldé CP, et al. (2012) The Dutch WEEE Flows. United Nations University, ISP-SCYCLE, Bonn, Germany.

33. Kuehr R (2016) Guiding Principles to Develop Ewaste Management Systems and Legislation. Solving the E-Waste Problem | Step White Paper pp: 1-15.

34. Awasthi AK, Li J (2017) Management of electrical and electronic waste: A comparative evaluation of China and India. Renewable and Sustainable Energy Reviews 76: 434-447.

35. EIU (2015) Global e-waste systems: Insights for Australia from other developed countries. A report for ANZRP by the Economist Intelligence Unit (EIU) pp: $1-25$.

36. Lodhia S, Martin N, Rice J (2017) Extended Producer Responsibility for waste televisions and computers: A regulatory evaluation of the Australian experience. Journal of Cleaner Production 164(15): 927-938.

37. McCann D, Wittmann A (2015) E-waste Prevention, Take-back System. Design and Policy Approaches. Solving the E-Waste Problem (Step) Green Paper pp: 1-24.

38. Forrest L, Denton SJ (2014) Management of electronic waste-Financial responsibility. Compliance and Risks. Cork Ireland pp: 1-41.

39. Schluep M, Manhart A, Osibanjo O, Rochat R, Isarin N (2011) Where are WEEE in Africa? Findings from the Basel Convention E-waste Africa Programme. Secretariat of the Basel Convention, UNEP.

40. Wittmann A, McCann D (2015) E-waste Prevention, Take- back System Design and Policy Approaches. Solving the e-waste problem (StEP) Initiative Green Paper E-waste Prevention, Take-back System Design and Policy Approaches, United Nations University.

41. Wang F, Kuehr R, Ahlquist D, Li J (2013) E-waste in China: a country report. United Nations University/StEP Initiative.

42. Minter A (2016) How We Think about E-Waste Is in Need of Repair. China and Ghana are looking less and less like electronic wastebaskets and more and more like leaders in a powerful, informal green economy.

43. Sinha-Khetriwal D, Philipp K, Schwaninger M (2005) A comparison of electronic waste recycling in Switzerland and in India. Environmental Impact Assessment Review 25(5): 492-504.

44. Park M (2012) E-waste and Obsolescence: Designing out toxicity. In Design Research Society 2012: Bangkok: Design Research Society 4: 1434-1442.

45. Golev A, Schmeda-Lopez D, Smart S, Corder G, McFarland E (2016) Where next on e-waste in Australia? Waste Management 58: 348-358. 